\title{
Platelet-Activating Factor Blockade Inhibits the T-Helper Type 17 Cell Pathway and Suppresses Psoriasis-Like Skin Disease in K5.hTGF- $\beta 1$ Transgenic Mice
}

\author{
Tej Pratap Singh, ${ }^{\star \dagger}$ Barbara Huettner, ${ }^{\dagger}$ \\ Harald Koefeler, ${ }^{\dagger}$ Gerlinde Mayer, ${ }^{*}$ \\ Isabella Bambach, ${ }^{*}$ Katrin Wallbrecht, ${ }^{\ddagger}$ \\ Michael P. Schön, ${ }^{\star}$ and Peter Wolf* \\ From the Research Unit for Photodermatology, Department of \\ Dermatology, and the Center for Medical Research, ${ }^{\dagger}$ Medical \\ University of Graz, Graz, Austria; and the Department of \\ Dermatology, Venereology, and Allergology, ${ }^{\ddagger}$ Georg August \\ University, Göttingen, Germany
}

Platelet-activating factor (PAF), a potent biolipid mediator, is involved in a variety of cellular transduction pathways and plays a prominent role in inducing inflammation in different organs. We used K5.hTGF- $\beta 1$ transgenic mice, which exhibit an inflammatory skin disorder and molecular and cytokine abnormalities with strong similarities to human psoriasis, to study the pathogenic role of PAF. We found that injecting PAF into the skin of transgenic mice led to inflammation and accelerated manifestation of the psoriatic phenotype by a local effect. In contrast, injecting mice with PAF receptor antagonist PCA-4248 lowered the PAF level (most likely by depressing an autocrine loop) and neutrophil, $\mathrm{CD}^{+} 8^{+}$cell (monocyte/macrophage), and $\mathrm{CD}^{+} \mathrm{T}$-cell accumulation in the skin and blocked progression of the psoriasis-like phenotype. This effect of PAF blockade was specific and similar to that of psoralen-UV-A and was paralleled by a decrease in abnormally elevated mRNA and/or protein levels of T-helper type 17 cell-related cytokines IL-17A, IL-17F, IL-23, IL-12A, and IL-6 and its transcription factor signal transducer and activator of transcription 3 . In contrast, PCA-4248 treatment up-regulated mRNA levels of cyclooxygenase-2 and IL-10 in dorsal skin and release of $\mathrm{IL}-10$ in serum and skin. Interfering with PAF may offer the opportunity to develop novel therapeutic strategies for inflammatory psoriasis and associated comorbidities, including metabolic syndrome and atherosclerosis, in which the $\mathrm{IL}-17$ axis may be involved. (Am J Pathol 2011, 178:699-708; DOI: 10.1016/j.ajpath.2010.10.008)
Platelet-activating factor (PAF; 1-O-alkyl-2-acetyl-snglycero-3-phosphocholine) is a biologically potent phospholipid mediator that plays a role in a variety of cellular signal transduction pathways. It is produced by and/or activates a variety of cells, including keratinocytes, platelets, mast cells, eosinophilic and polymorphonuclear leukocytes, monocytes, macrophages, endothelial cells, and fibroblasts. ${ }^{1-3}$ Platelet-activating factor can induce inflammatory events in the skin, including vascular changes and cellular infiltration. It also promotes the migration of leukocytes to sites of inflammation. ${ }^{4}$ Binding of the specific PAF receptor, a unique seven-transmembrane-spanning G-coupled protein, induces a plethora of downstream effects, including activation of the mitogen-activated protein kinase pathway, activation of phospholipase, and the biosynthesis of cyclooxygenase-2 (COX-2) and eicosanoids (including prostaglandins) and a variety of cytokines, including tumor necrosis factor- $\alpha$ (TNF- $\alpha$ ), IL-1, IL-6, and IL-8. ${ }^{4,5}$ Activation of the epidermal PAF receptor results in increased biosynthesis of PAF (by an autocrine loop). ${ }^{6,7}$

Several studies have implicated PAF in the pathogenesis of psoriasis. For example, PAF may particularly contribute to the acute phase of leukotactic inflammation in patients with pustular psoriasis. ${ }^{8}$ Functionally, PAF enhances chemotaxis, aggregation, and degranulation of peripheral blood polymorphonuclear leukocytes in vitro and increases vascular permeability in vivo. ${ }^{9}$ It may have priming effects for leukocytes and endothelial cells and enhance inflammatory events. Indeed, plasma levels of PAF were found to be increased in patients with psoriasis, and a significant decrease in those levels was ob-

Supported by grants from the Austrian National Bank Jubilee funds (11729 and 13279) and by the PhD Program in Molecular Medicine, subprogram in Molecular Inflammation (MOLIN), Medical University of Graz (T.P.S.).

Accepted for publication October 21, 2010.

The authors declare that no conflict of interest exists.

Supplemental material for this article can be found at http://ajp. amjpathol.org and at doi:10.1016/j.ajpath.2010.10.008.

Address reprint requests to Peter Wolf, M.D., Research Unit for Photodermatology, Department of Dermatology, Medical University of Graz, Auenbruggerplatz 8, A-8036 Graz, Austria. E-mail: peter.wolf@medunigraz.at. 
served with clinical improvement after treatment. ${ }^{8}$ Moreover, elevated levels of arachidonic acid and eicosanoids and elevated expression of human nonpancreatic phospholipase $A_{2}$ were measured in psoriatic tissue. ${ }^{10}$ Phospholipase $A_{2}$ is one of the key enzymes for PAF formation because it enzymatically cleaves arachidonic acid from the sn-2 position of cell membrane phosphatidylcholine, and an acetyl residue is subsequently transferred to the free hydroxyl from CoASAc to form biologically active PAF. ${ }^{3}$ Besides, PAF was identified and isolated in scales from psoriatic patients. ${ }^{2,11}$ Last but not least, Travers et $\mathrm{al}^{12,13}$ suggested that PAF and its receptor play a direct role in keratinocyte pathogenesis.

We recently used K5.hTGF- $\beta 1$ transgenic mice, ${ }^{14,15}$ which exhibit a skin phenotype and molecular and cytokine abnormalities with strong similarities to human psoriasis, to study the therapeutic mechanisms of psoralenUV-A (PUVA) photochemotherapy and observed that impaired function of regulatory $\mathrm{T}$ cells and increased cytokine levels of the IL-23/T-helper type 17 cell (Th17) pathway were responsible for the psoriatic phenotype in this mouse model. ${ }^{16}$ Treatment of K5.hTGF- $\beta 1$ transgenic mice with PUVA not only cleared the psoriatic skin manifestations but also suppressed the Th1 milieu and the IL-23/Th17 pathway and induced the Th2 pathway and $\mathrm{IL}-10$-producing $\mathrm{CD} 4^{+} \mathrm{CD} 25^{+} \mathrm{Foxp} 3^{+}$regulatory $\mathrm{T}$ cells with disease-suppressive activity in K5.hTGF- $\beta 1$ transgenic mice. The PAF pathway may affect T-cell responses and favor development of the inflammatory Th17 pathway, ${ }^{17}$ in which $\mathrm{T}$ cells produce the proinflammatory cytokines IL-17A (IL-17) and IL-17F and, to a lesser extent, TNF and IL-6. ${ }^{18}$ Indeed, expression of IL-17 seems to be increased in human autoimmune diseases, including multiple sclerosis, ${ }^{19,20}$ rheumatoid arthritis, ${ }^{21,22}$ lupus erythematosus, ${ }^{22}$ and psoriasis ${ }^{23}$ as well as in animal models of autoimmunity. ${ }^{24} \mathrm{We}$, therefore, were interested in testing the hypothesis that PAF/PAF receptor interaction plays a role in induction of the psoriatic phenotype and Th17 cytokine abnormalities in K5.hTGF- $\beta 1$ transgenic mice.

\section{Materials and Methods}

\section{Animals}

K5.hTGF- $\beta 1$ transgenic mice (on Hsd:ICR/CD-1R background) expressing wild-type (WT) transforming growth factor (TGF)- $\beta 1$ in the epidermis were used, as previously described. ${ }^{16}$ All the animals were maintained with alternating 12-hour light and dark cycles in temperature- and humidity-controlled facilities approved by the Austrian government. Water and food were provided ad libitum. All the animal procedures were approved by the Austrian government, Federal Ministry for Science and Research, through protocol no. BMBWK-66.010/0034-BrGT/2006 and 66.010/ 79-C/GT/2007. Mice were 12 to 16 weeks old at the start of the experiment and were age and sex matched in each experiment.

\section{PAF or Serotonin Injection}

Dorsal skin of the mice was injected intracutaneously with 100 ng of PAF ( $\beta$-Acetyl-y-O-alkyl-L- $\alpha$-phosphatidylcholine from bovine heart lecithin; Sigma-Aldrich, St. Louis, MO) or $5 \mu \mathrm{g}$ of serotonin (Sigma-Aldrich) or bovine serum albumin vehicle control in a final volume of $50 \mu \mathrm{L}$. After 24 and 72 hours, biopsy specimens were collected for H\&E staining.

\section{PAF or Serotonin Receptor Blockade}

The PAF receptor antagonist PCA-4248 and the serotonin receptor antagonist ketanserin tartrate were purchased from Biomol Research Labs Inc. (Plymouth Meeting, PA). Stock solutions were prepared by dissolving PCA-4248 or ketanserin tartrate in dimethyl sulfoxide and diluted further in PBS before injection into mice. Mice were injected with PCA-4248 or ketanserin tartrate i.p. $(10 \mathrm{mg} /$ $\mathrm{kg}$ ) twice weekly for 4 weeks.

\section{PUVA Treatment}

The backs of the mice were shaved using an electric clipper 1 day before PUVA treatment. The remaining hair was then removed by the application of a commercial depilation cream for 3 to 5 minutes (Depilan sensitive) and subsequent cleaning with water. Mice were painted on their backs with $200 \mu \mathrm{L}$ of 8-methoxypsoralen (Sigma-Aldrich) in 95\% ethanol (at a concentration of $0.1 \mathrm{mg} / \mathrm{ml}$ ) or were left untreated. The mice were then kept for 15 minutes in individual compartments of standard cages to allow penetration of 8-methoxypsoralen. Irradiation with UV-A was performed using a Waldmann UV236A irradiation system equipped with two fluorescent PL 36W/09-PUVA light tubes (emission range, 315 to $400 \mathrm{~nm}$; peak, $365 \mathrm{~nm}$; Waldmann Medizintechnik, Villingen-Schwenningen, Germany) at a mean irradiance of $8.55 \mathrm{~mW} / \mathrm{cm}^{2}$, as previously described. ${ }^{16}$ The PUVA was administered to the dorsal skin of the mice on a subphototoxic level at a dose of $0.25 \mathrm{~J} / \mathrm{cm}^{2}$ or near-phototoxic level of $0.50 \mathrm{~J} / \mathrm{cm}^{2} \mathrm{UV}$-A twice weekly (Monday and Thursday or Tuesday and Friday) for 4 weeks.

\section{Skin Disease Severity Score}

A specific mouse skin disease severity score composed of a rating from 0 to 3 for the symptoms of erythema, infiltration, and scaling based on the macroscopic appearance of the skin was used weekly to monitor the skin status of individual mice in a blinded manner, as previously described. ${ }^{16}$ Briefly, each symptom was scored separately as 0 (not present), 1 (mild), 2 (moderate), or 3 (severe). The scores were summed up, taking into consideration the area involved, resulting in a maximal score of 9 .

\section{Tissue Collection}

Mice were sacrificed 48 hours after the final treatment, and blood, skin, and ear samples were collected. Serum was frozen and stored at $-70^{\circ} \mathrm{C}$ for enzyme-linked immunosorbent assay (ELISA). Approximately $1 \mathrm{~cm}^{2}$ of central dorsal skin per mouse was excised, fixed immediately in $4 \%$ buff- 
ered formaldehyde, processed routinely, and sectioned at 4 $\mu \mathrm{m}$ for H\&E staining. In addition, fresh skin tissue was subjected to homogenization for mass spectrometry or was submerged in RNAlater solution (Applied Biosystems, Foster City, CA) and stored at $-70^{\circ} \mathrm{C}$ for later mRNA analysis.

\section{Immunohistochemical Analysis}

Stainings were performed on paraffin-embedded sections of mouse dorsal skin with monoclonal rat antimouse CD68 (clone, FA-11; Abcam, Cambridge, England) (1:50) or polyclonal rabbit antimouse CD3 (Abcam) (1:100). Briefly, primary antibody was applied after pretreatment of the sections with EDTA at pH 8. Dako biotinylated polyclonal rabbit antirat Igs or Dako Multi-Link antigoat, antimouse, and antirabbit Igs Multilink system (Dako, Glostrup, Denmark) was used for visualization of the staining, according to the manufacturer's instructions.

\section{Immunofluorescence Staining}

Direct or indirect stainings were performed on paraffin-embedded sections of mouse dorsal skin with either phycoerythrin-conjugated antimouse rat IL-10 (clone, JES5-16E3; BD Pharmingen, San Diego, CA) (1:50) or antimouse rabbit signal transducer and activator of transcription 3 (STAT3) (Abcam) (1:50). Goat antirabbit lgG fluorescein isothiocyanate (Abcam) (1:100) was used as secondary antibody for STAT3. Briefly, antibody was applied after pretreatment of the sections with EDTA at $\mathrm{pH} 8$ followed by blocking with $5 \%$ bovine serum albumin/0.5 Tween 20. After incubation at room temperature for 1 hour, slides were incubated with secondary antibody and coverslips were mounted onto the slides using VECTASHIELD mounting medium with DAPI (Vector Laboratories, Burlingame, CA). Images were acquired by using a DP71 digital camera (Olympus, Center Valley, PA) attached to an Olympus BX51 microscope.

\section{Assessment of Microscopic Skin Inflammation}

Epidermal hyperplasia was quantified in dorsal or ear skin of H\&E-stained sections by counting epidermal cell layers and measuring the thickness of the epidermis from the basal layer to the stratum corneum using the calibrated eyepiece micrometer of a microscope. Semiquantitative scoring of the inflammatory infiltrate in the upper or lower dermis was performed in the dorsal skin of H\&E-stained sections as follows: 0 , none; 1 , mild; 2 , moderate; and 3 , severe in at least 10 randomly selected areas per section (at final magnification, $\times 100$ ). The number of neutrophils in $\mathrm{H} \& \mathrm{E}$ sections and $\mathrm{CD} 68^{+}$cells (monocytes/macrophages) and $\mathrm{CD}^{+} \mathrm{T}$ cells in the dermis of immunohistochemically stained sections from dorsal skin was assessed in at least 10 to 15 randomly selected areas per section (at final magnification, $\times 200)$. All measurements were performed in a blinded manner. Results were first averaged per mouse and then were averaged per treatment group for statistical analysis. Images were acquired by using a DP71 digital camera attached to an Olympus BX51 microscope.

\section{PAF Analysis Using Mass Spectrometry}

Mouse skin was homogenized in $2 \mathrm{ml}$ of PBS/methanol (1/1 $\mathrm{v} / \mathrm{v})$. Each sample was spiked with $25 \mathrm{ng}$ of 1-O-Octadecyl2-butanoyl-sn-glycero-3-phosphocholin (Avanti Polar Lipids Inc., Alabaster, AL) as internal standard immediately. Subsequently, lipids were extracted according to the method of Bligh and Dyer. ${ }^{25}$ Lipid extracts were taken to dryness and were resuspended in $200 \mu \mathrm{L}$ of chloroform/methanol (2/1 v/v). A HyPURITY Advance C18 (polar embedded), $100 \times$ 2.1-mm, 3- $\mu \mathrm{m}$ column (Thermo Fisher Scientific, Waltham, MA) was used. The gradient ran from $0 \%$ to $95 \%$ B in 1 minute, then to $100 \% B$ in another 12 minutes, where it was held for 8 minutes. The flow rate was $250 \mu \mathrm{L} / \mathrm{min}$ (4000 QTRAP; Applied Biosystems, coupled to an 1100 HPLC; Agilent, Palo Alto, CA). Data acquisition was performed using multiple reaction monitoring scanning. The spray voltage was set to $5000 \mathrm{~V}$, curtain gas to $10 \mathrm{psi}$, source temperature to $400^{\circ} \mathrm{C}$, declustering potential to $90 \mathrm{~V}$, and collision energy to $35 \mathrm{~V}$ for all analytes. The nebulizer gas was at $60 \mathrm{psi}$, and the turbo gas was at 50 psi. Peak areas were calculated using Analyst software (Applied Biosystems) for PAF, identified by mass, fragmentation, and retention time. The amount of PAF was calculated using the standard curve method.

\section{Cytokine ELISA}

The Th1/Th2/Th17 cytokines Multi-Analyte ELISArray Kit (SABiosciences, Frederick, MD) was used to analyze a panel of 12 cytokines involved in Th cell biology using a conventional ELISA protocol according to the manufacturer's instructions. The cytokines represented by this array are IL-2, IL-4, IL-5, IL-6, IL-10, IL-12, IL-13, IL-17A, IL-23, interferon- $\gamma$, TNF- $\alpha$, and TGF- $\beta 1$.

\section{Quantitative RT-PCR}

RNA was isolated from mouse dorsal skin using the QIAGEN Fibrous Mini Kit (QIAGEN Inc., Valencia, CA). RNA was reverse transcribed using the First Strand cDNA Synthesis Kit (Roche Diagnostics GmbH, Mannheim, Germany), and quantitative RT-PCR was performed using pretested primers to STAT3, IL-17A, IL-17F, IL-12A, IL-6, COX-2, and IL-10 (SuperArray Biosciences Corp., Frederick, $\mathrm{MD})$. The reactions were run on an Applied Biosystems $7900 \mathrm{HT}$ system by using RT ${ }^{2}$ SYBR Green/ROX qPCR Master Mix (SuperArray Biosciences Corp). The $\Delta \Delta \mathrm{Ct}$ method was used to normalize transcript to glyceraldehyde-3-phosphate dehydrogenase and to calculate fold change compared with the WT control.

\section{Statistical Analysis}

Data are expressed as mean \pm SEM. Statistical differences among experimental groups were determined by using unpaired or paired two-tailed $t$-tests as appropriate. Statistical significance was set at $P<0.05$. 
A

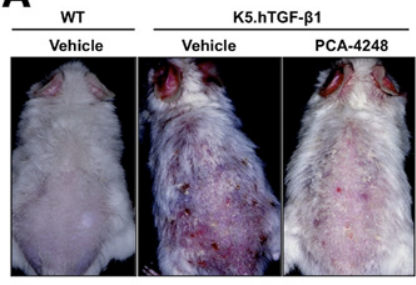

C

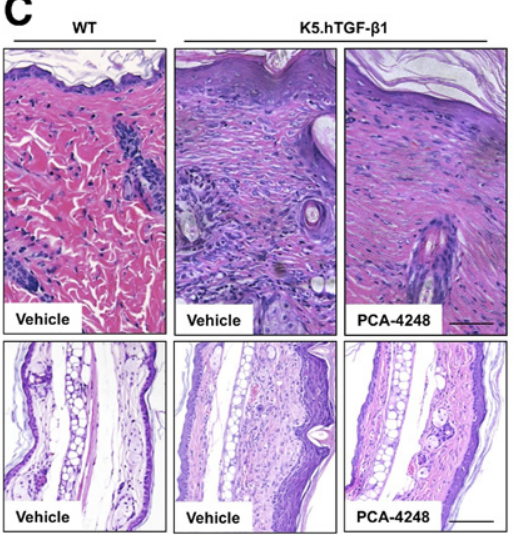

B
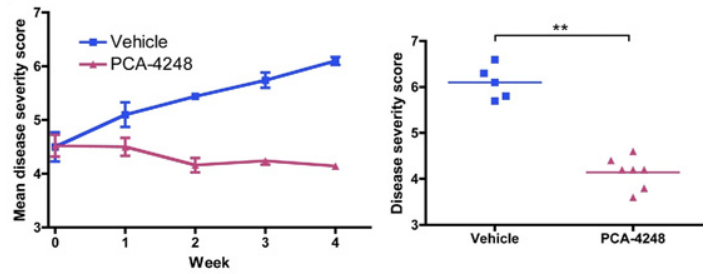

D

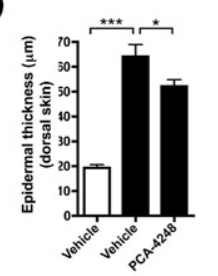

(1)
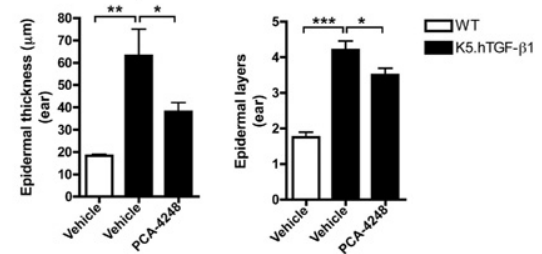

Figure 1. The PAF receptor antagonist PCA- 4248 blocks macroscopic and microscopic psoriatic skin disease progression in K5.hTGF- $\beta 1$ transgenic mice. The WT or K5.hTGF- $\beta 1$ transgenic mice were injected i.p. twice weekly for 4 weeks with PCA-4248 (10 mg/kg) or its vehicle. A: Macroscopic presentation of WT or K5.hTGF- $\beta 1$ transgenic mice treated with either PCA- 4248 or vehicle. B: A specific score (ranging from 0 to a maximum of 9) was used to monitor macroscopic disease severity in the mice. Results are given as either mean disease score during the 4-week treatment regimen (left) or disease severity score at week 4 (right). C: Representative images of H\&E-stained sections from the dorsal skin or ear of a mouse from the different treatment groups. Scale bar $=100 \mu \mathrm{m}$. D: Evaluation of histologic features, including epidermal thickness and epidermal layers. Data shown are from one representative experiment, with $n=5$ to 10 per treatment group. ${ }^{*} P \leq 0.05$. ${ }^{* * *} P \leq 0.01$. ${ }^{* * *} P \leq 0.001$. Error bars represent SEM.

\section{Results}

\section{PAF Receptor Blockade Prevents Whereas PAF Accelerates Progression of Skin Disease in K5.hTGF- $\beta 1$ Transgenic Mice}

To study the role of PAF and its receptor in the pathogenesis of psoriasis-like skin disease in the K5.hTGF- $\beta 1$ transgenic mouse model, we used the PAF antagonist PCA-4248. This antagonist has been previously shown to inhibit not only UV-induced immunologic alterations ${ }^{3,26,27}$ but also nonmelanoma skin cancer induction and progression and UV-induced skin damage in hairless mice, ${ }^{28}$ as well as experimental human melanoma lung metastasis in nude mice. ${ }^{4}$ We injected WT or K5.hTGF- $\beta 1$ transgenic mice with either the PAF antagonist PCA-4248
A
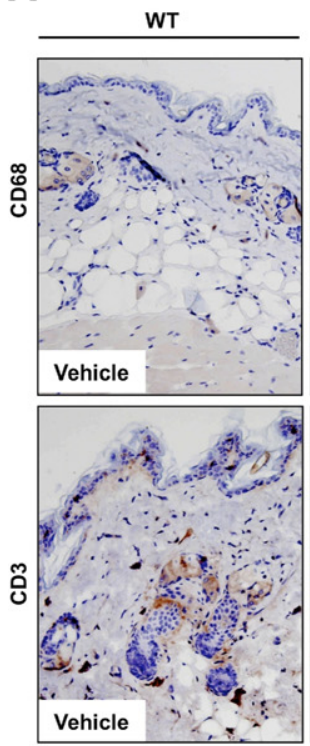

K5.hTGF- $\beta 1$
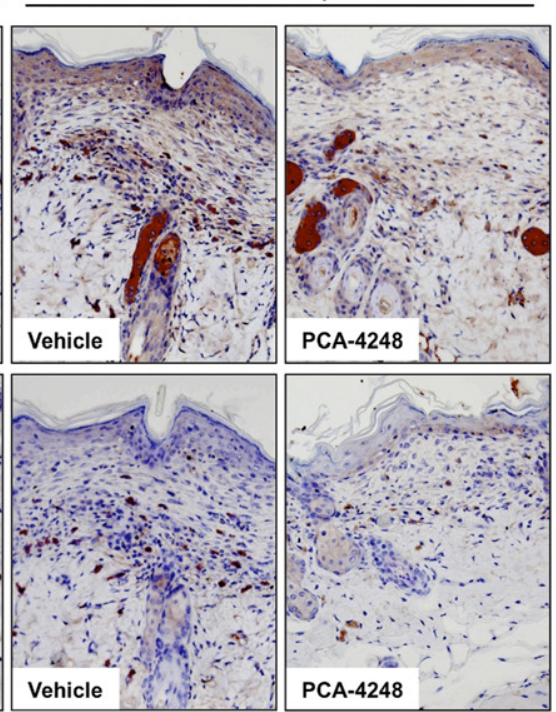

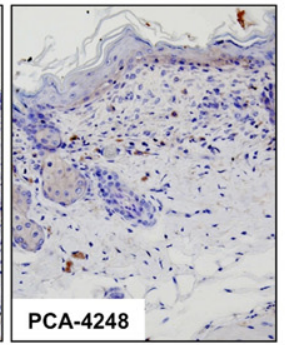

B
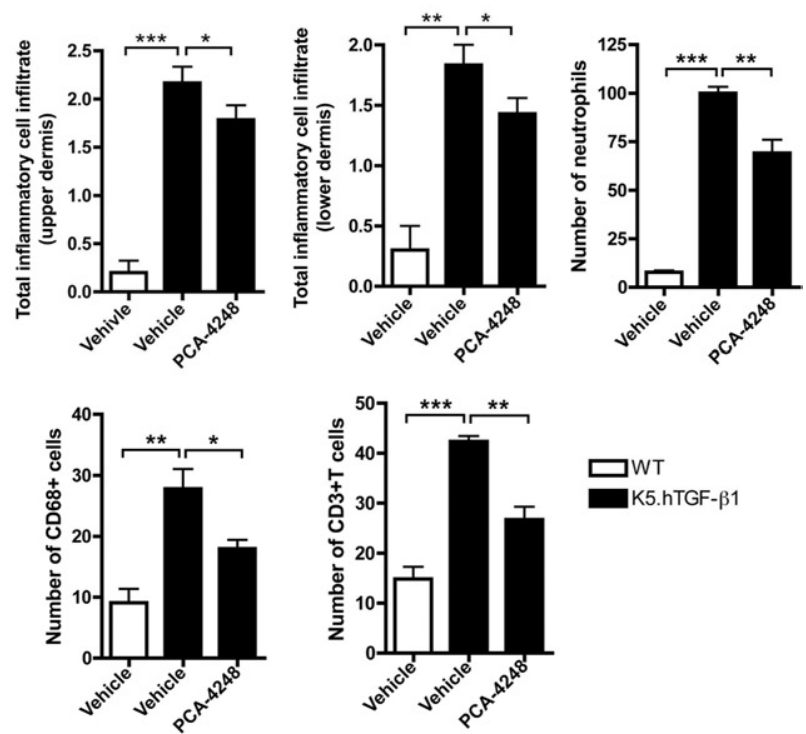

Figure 2. Injection with PCA- 4248 decreases accumulation of different inflammatory cells in the dermis of K5.hTGF- $\beta 1$ transgenic mice. The WT or K5.hTGF- $\beta 1$ transgenic mice were injected i.p. twice weekly for 4 weeks with PCA- $4248(10 \mathrm{mg} / \mathrm{kg})$ or its vehicle. Dorsal skin samples were collected at the end of the $4-\mathrm{week}$ treatment regimen for assessment of inflammatory cell infiltrate. A: Representative images of immunohistochemically stained sections of $\mathrm{CD} 68^{+}$cells and $\mathrm{CD}^{+}{ }^{+}$cells from the dorsal skin of a mouse from the different treatment groups. B: Evaluation of histologic or immunohistochemical sections included total inflammatory cell infiltrate $(0$, no; 1 , mild; 2 , moderate; and 3, severe) in the upper or lower dermis and number of neutrophils, CD $68^{+}$cells (monocytes/macrophages), and CD $3^{+} \mathrm{T}$ cells. Data shown are from one representative experiment, with $n=3$ to 10 per treatment group. ${ }^{*} P \leq 0.05$. ${ }^{* *} P \leq 0.01$. ${ }^{* * * * *} P \leq 0.001$. Error bars represent SEM. 
Table 1. PAF Accelerates the Skin Disease Phenotype of K5.hTGF- $\beta 1$ Transgenic Mice

\begin{tabular}{|c|c|c|c|c|c|c|c|c|}
\hline \multirow[b]{4}{*}{ Histologic parameter } & \multicolumn{8}{|c|}{ Time point and treatment* } \\
\hline & \multicolumn{4}{|c|}{24 hours } & \multicolumn{4}{|c|}{72 hours } \\
\hline & \multicolumn{2}{|c|}{ WT } & \multicolumn{2}{|c|}{ K5.hTGF- $\beta 1$} & \multicolumn{2}{|c|}{ WT } & \multicolumn{2}{|c|}{ K5.hTGF- $\beta 1$} \\
\hline & Vehicle & PAF & Vehicle & PAF & Vehicle & PAF & Vehicle & PAF \\
\hline Skin thickness $(\mu \mathrm{m})$ & $15.1 \pm 1.3$ & $18.7 \pm 2.0$ & $24.8 \pm 2.1$ & $38.7 \pm 4.3^{\dagger}$ & $21.7 \pm 2.2$ & $26.8 \pm 5.5$ & $31.5 \pm 3.7$ & $54.4 \pm 2.9^{\dagger}$ \\
\hline No. of epidermal layers & $1.8 \pm 0.3$ & $2.0 \pm 0.3$ & $3.0 \pm 0.2$ & $3.4 \pm 0.1$ & $1.6 \pm 0.1$ & $2.0 \pm 0.2$ & $3.0 \pm 0.3$ & $4.0 \pm 0.3^{\dagger}$ \\
\hline Total dermal cell infiltrate score & $0.3 \pm 0.1$ & $0.3 \pm 0.1$ & $1.5 \pm 0.1$ & $2.3 \pm 0.2^{\ddagger}$ & $0.3 \pm 0.1$ & $0.4 \pm 0.2$ & $1.7 \pm 0.1$ & $2.5 \pm 0.2^{\ddagger}$ \\
\hline $\begin{array}{l}\text { No. of neutrophils per field } \\
(\times 200)\end{array}$ & $8.5 \pm 1.4$ & $13.8 \pm 1.8$ & $55.9 \pm 6.0$ & $76.8 \pm 9.4$ & $7.8 \pm 0.9$ & $18.3 \pm 1.9^{\ddagger}$ & $59.8 \pm 4.9$ & $93.5 \pm 5.0^{\ddagger}$ \\
\hline
\end{tabular}

Mice were injected intracutaneously with PAF (100 ng) or with vehicle control. Biopsy samples were collected at injection sites at different time points after injection (24 and 72 hours) for histologic evaluation, as defined in Materials and Methods.

${ }^{*}$ Data are given as mean \pm SEM.

${ }^{\dagger} P<0.05$.

${ }^{\ddagger} P<0.01$ (unpaired $t$-test) comparing the respective PAF versus vehicle treatment values ( $n=4$ to 8 per treatment and time point).

or PBS as vehicle control twice weekly for 4 weeks. We found that treatment with PCA-4248 blocked the psoriatic disease progression in K5.hTGF- $\beta 1$ transgenic mice compared with in vehicle-injected control littermates (Figure 1, A and B). The stop of progression of skin disease in transgenic mice was paralleled by the reduced histologic alterations observed in PCA-4248treated K5.hTGF- $\beta 1$ transgenic mice compared with vehicle-injected control littermates (Figure 1, C and D). Whereas vehicle-treated K5.hTGF- $\beta 1$ transgenic mice exhibited a hyperplastic epidermis of approximately four cell layers and a thickness of $>60 \mu \mathrm{m}$ and a dermis with a superficial mixed inflammatory infiltrate consisting of mononuclear cells and neutrophils, $\mathrm{CD}^{+} 8^{+}$cells, and $\mathrm{CD}^{+} \mathrm{T}$ cells, such skin alterations were significantly diminished in the skin of PCA-4248-injected transgenic mice after 4 weeks of treatment (Figure 2B). The PCA4248 injection particularly reduced the mean \pm SEM number of neutrophils (from $100.0 \pm 3.2$ to $69.2 \pm 6.8$ ), $\mathrm{CD}^{+} 8^{+}$cells (from $27.8 \pm 3.2$ to $17.9 \pm 1.4$ ), and CD3 ${ }^{+}$ T cells (from $42.4 \pm 1.1$ to $26.7 \pm 2.6$ ) in the dermis of transgenic mice (Figure $2 \mathrm{~B}$ ). In contrast, we found that injecting PAF into the skin of transgenic mice led to inflammation and accelerated the manifestation of the psoriatic phenotype by a local effect, as observed on the macroscopic level (data not shown) and confirmed on the microscopic level by density of skin infiltration and epidermal hyperplasia. The effects of PAF in accelerating the disease phenotype were more prominent after 72 hours compared with 24 hours after single intracutaneous injection (Table 1). In addition to being a PAF receptor antagonist, PCA-4248 may also act as a serotonin receptor antagonist. 29,30 We, therefore, looked for the effect of the serotonin receptor antagonist ketanserin tartrate on the psoriatic phenotype in K5.hTGF- $\beta 1$ transgenic mice. However, we found that blocking serotonin receptor with ketanserin tartrate did not affect macroscopic skin phenotype (see Supplemental Figure S1A at http://ajp.amjpathol.org) or microscopic skin alterations in the transgenic mice (data not shown). Furthermore, intracutaneous injection of serotonin did not accelerate the psoriatic disease phenotype of the transgenic mice (see Supplemental Figure S1B at $h$ ttp://ajp. amjpathol.org). These findings indicated that the effect of
PCA-4248 in blocking PAF was specific and that serotonin did not play a (major) role in psoriatic skin disease abnormality of K5.hTGF- $\beta 1$ transgenic mice.

\section{PAF Receptor Blockade Down-Regulates the STAT3 and Th17 Cytokine Pathway But Up-Regulates IL-10 in K5.hTGF- $\beta 1$ Transgenic Mice}

We found that blockade of PAF receptor with the PAF receptor antagonist $\mathrm{PCA}-4248$ depressed the abnormally elevated protein levels of IL-6, IL-12, IL-17A, and IL-23 by $36 \%, 52 \%, 76 \%$, and $61 \%$ respectively, and increased IL-10 expression by $44 \%$ in the serum of K5.hTGF- $\beta 1$ transgenic mice (Figure $3 \mathrm{~A}$ ). However, it did not significantly affect or reduce serum levels of IL-2, IL-4, IL-5, IL-13, interferon- $\gamma$, and TNF- $\alpha$. We also found that PAF receptor blockade with $\mathrm{PCA}-4248$ significantly reduced mRNA expression of STAT3, IL-17A, IL-17F, IL-12A, and IL-6 and up-regulated the mRNA expression of COX-2 and IL-10 in the dorsal skin of K5.hTGF- $\beta 1$ transgenic mice compared with vehicle-injected mice (Figure 3D). Immunofluorescent staining of dorsal mouse skin revealed that PCA-4248 injection reduced the number and intensity of STAT3-positive cells, particularly in the epidermis, and increased the number of IL-10-positive cells in the dermis of transgenic mice (Figure 3, B and C). Weak IL-10 staining was also present in the basal layers of the epidermis, but there was no difference among the treatment groups (data not shown).

\section{PAF Receptor Blockade with Receptor Antagonist PCA-4248 and PUVA Normalizes the PAF Level in the Skin of K5.hTGF- $\beta 1$ Transgenic Mice}

We hypothesized that PAF plays a role in the pathogenesis of the psoriasis-like skin disease in K5.hTGF- $\beta 1$ transgenic mice. To determine PAF levels and study the potential effect of PAF receptor blockade by an autocrine loop ${ }^{6,7}$ on PAF itself, we measured PAF levels directly in 
A

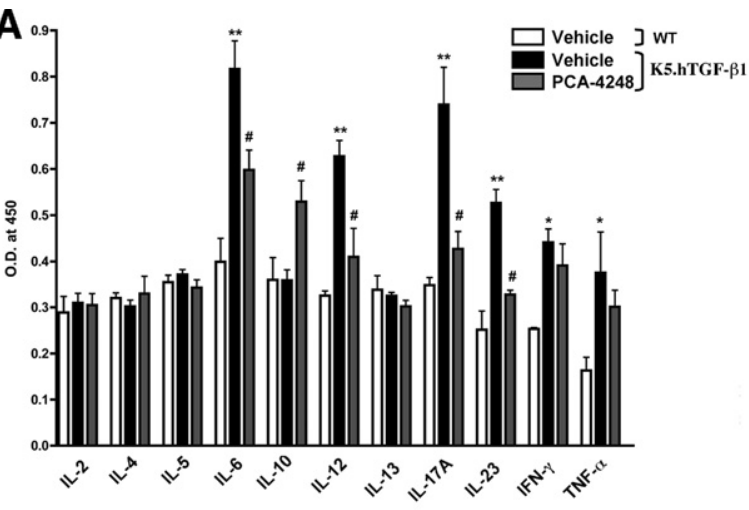

B
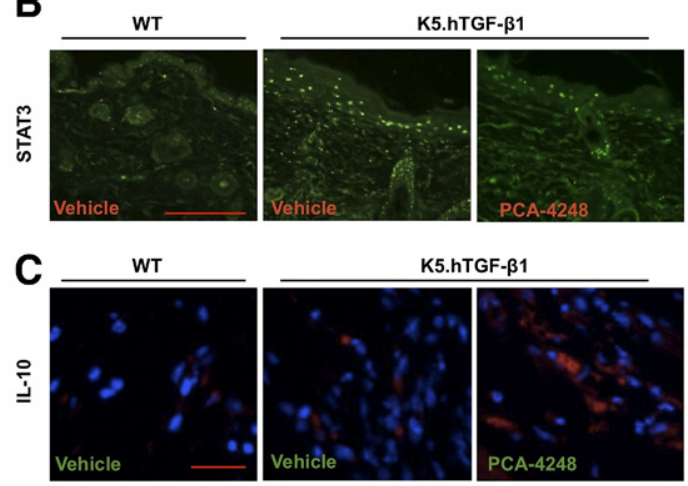

D
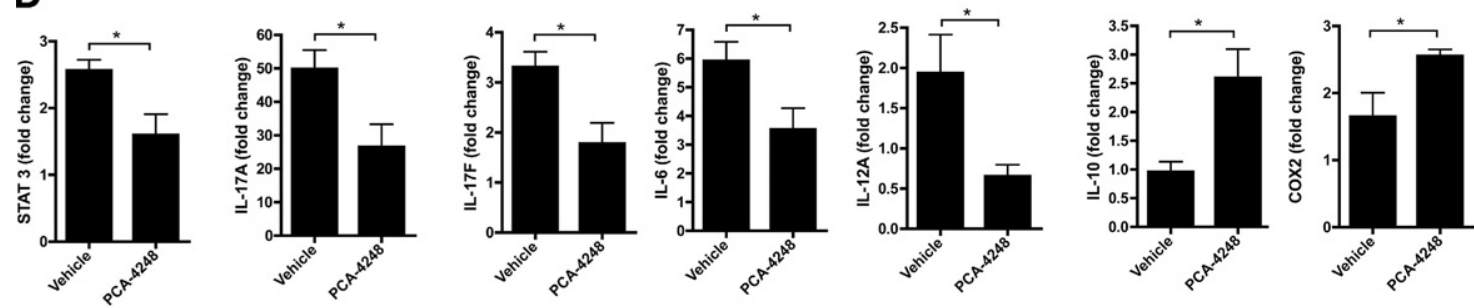

Figure 3. Effect of PCA-4248 on mRNA and/or protein levels of Th1-, Th2-, and Th17-related cytokines and transcription factor STAT3 and COX-2 in K5.hTGF- $\beta 1$ transgenic mice. The WT or K5.hTGF- $\beta 1$ transgenic mice were injected i.p. twice weekly for 4 weeks with PCA- 4248 ( 10 mg $/ \mathrm{kg}$ ) or its vehicle. A: Serum samples were collected at the end of the 4-week treatment regimen from either vehicle-treated WT or vehicle- or PCA-4248-treated K5.hTGF- $\beta 1$ transgenic mice. A multicytokine ELISA was performed to analyze the relative levels of IL-2, IL-4, IL-5, IL-6, IL-10, IL-12, IL-13, IL-17A, IL-23, interferon- $\gamma$, and TNF- $\alpha$. Data shown are from one representative experiment, with $n=3$ to 4 per treatment group. ${ }^{*} P \leq 0.05 ;{ }^{* *} P \leq 0.01$, vehicle-treated K5.hTGF- $\beta 1$ vs vehicle-treated WT mice. ${ }^{*} P \leq 0.05$, PCA-4248-treated versus vehicle-treated K5.hTGF- $\beta 1$ mice. O.D., optical density. Immunofluorescent staining of STAT3 (B) and IL-10 (C) (blue: DAPI; red: IL-10) protein in dorsal skin. Scale bars: $200 \mu \mathrm{m}(\mathbf{B}) ; 100 \mu \mathrm{m}(\mathbf{C})$. D: Quantitative RT-PCR was performed at the end of the 4-week treatment regimen from either vehicle-treated WT or vehicle- or PCA- 4248 -treated K5.hTGF- $\beta 1$ transgenic mice with RNA isolated from individual mouse dorsal skin for transcription factors STAT3 and transcripts encoding IL-17A, IL-17F, IL-6, IL-12A, IL-10, and COX-2. Data shown are from one representative experiment, with $n=5$ to 7 per treatment group. ${ }^{*} P \leq 0.05$. Error bars represent SEM.

the skin of the mice by means of mass spectrometry. We found that vehicle-injected K5.hTGF- $\beta 1$ transgenic mice had significantly increased mean \pm SEM PAF levels $(0.81 \pm 0.16 \mathrm{ng} / 100 \mathrm{mg})$ in the skin compared with WT littermates $(0.10 \pm 0.10 \mathrm{ng} / 100 \mathrm{mg})$ at the end of the 4-week treatment protocol (Figure 4A; see Supplemental Figure S2 at http://ajp.amjpathol.org). The PAF receptor blockade with the antagonist PCA-4248 (but not vehicle control) reduced the mean \pm SEM PAF levels in the skin of K5.hTGF- $\beta 1$ transgenic mice to $0.11 \pm 0.02 \mathrm{ng} / 100$ $\mathrm{mg}$, a level similar to that observed in WT control mice (Figure 4). We previously demonstrated that PUVA given at subphototoxic $\left(0.25 \mathrm{~J} / \mathrm{cm}^{2}\right)$ or near-phototoxic $(0.50$ $\mathrm{J} / \mathrm{cm}^{2}$ ) doses were effective in clearing psoriasis-like skin symptoms in K5.hTGF- $\beta 1$ transgenic mice. We, therefore, were interested in determining the effect of PUVA on PAF and found that both PUVA doses, similar to PCA-4248, reduced the mean \pm SEM PAF levels in the skin of K5.hTGF- $\beta 1$ transgenic mice to $0.17 \pm 0.06$ and $0.29 \pm$ 0.10 at $0.25 \mathrm{~J} / \mathrm{cm}^{2}$ and $0.50 \mathrm{~J} / \mathrm{cm}^{2}$, respectively (Figure 4A). The trend that the PAF-depressing effect of the lower PUVA dosage of $0.25 \mathrm{~J} / \mathrm{cm}^{2}$ was greater than that of the higher dose of $0.5 \mathrm{~J} / \mathrm{cm}^{2}$ is consistent with the potential role of PAF in the pathogenesis of the skin disease in K5.hTGF- $\beta 1$ transgenic mice, in which the lower, subphototoxic PUVA dose was also slightly more effective in reducing the psoriasis-like skin symptoms in the mice. ${ }^{16}$ This also is in line with the clinical knowledge that under certain circumstances, PUVA doses that are too high can trigger or aggravate psoriasis by the so-called Koebner phenomenon. ${ }^{27}$ Moreover, we previously provided evidence that exposure of normal mouse skin may lead to the production of PAF and/or PAF-like molecules with immunosuppressive properties, depending on the PUVA dosage used. ${ }^{27}$

\section{Discussion}

The PAF receptor blockade not only stopped disease progression at the macroscopic and microscopic levels (Figures 1 and 2) but also reduced the PAF level in the skin (Figure 4). Although the exact mechanism by which PAF receptor blockade reduces PAF levels remains to be determined; the most likely explanation is simple interruption of the known PAF autocrine loop and/or interference with leukocyte (eg, polymorphonuclear leukocyte) infiltration into the skin; the PAF receptor antagonist is inhibiting PAF formation, especially because these cells produce large amounts of this mediator. ${ }^{6,7}$

We also found that blockade of the PAF receptor with the antagonist PCA-4248 depressed the abnormally elevated protein levels of IL-6, IL-12, IL-17A, and IL-23 and increased IL-10 levels in serum (Figure $3 A$ ) and significantly reduced mRNA expression of STAT3, IL-17A, IL$17 \mathrm{~F}, \mathrm{IL}-12 \mathrm{~A}$, and IL-6 in the dorsal skin of transgenic mice (Figure 3D). This is important because recent studies described the significance of the Th17 pathway and its involvement in model systems of autoimmunity, including 
A

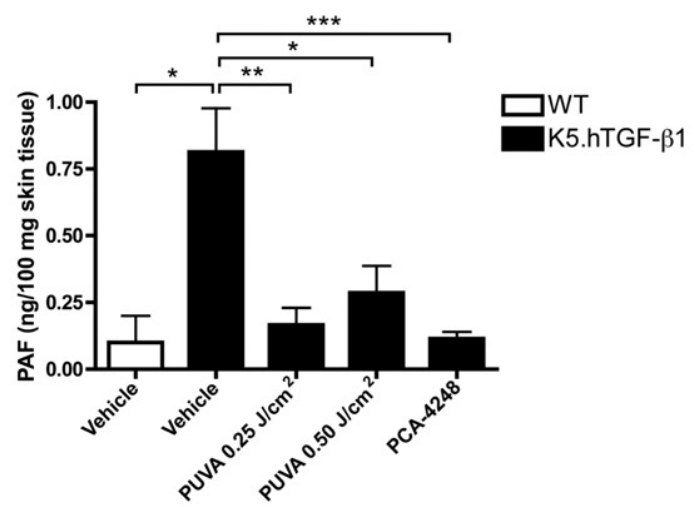

B
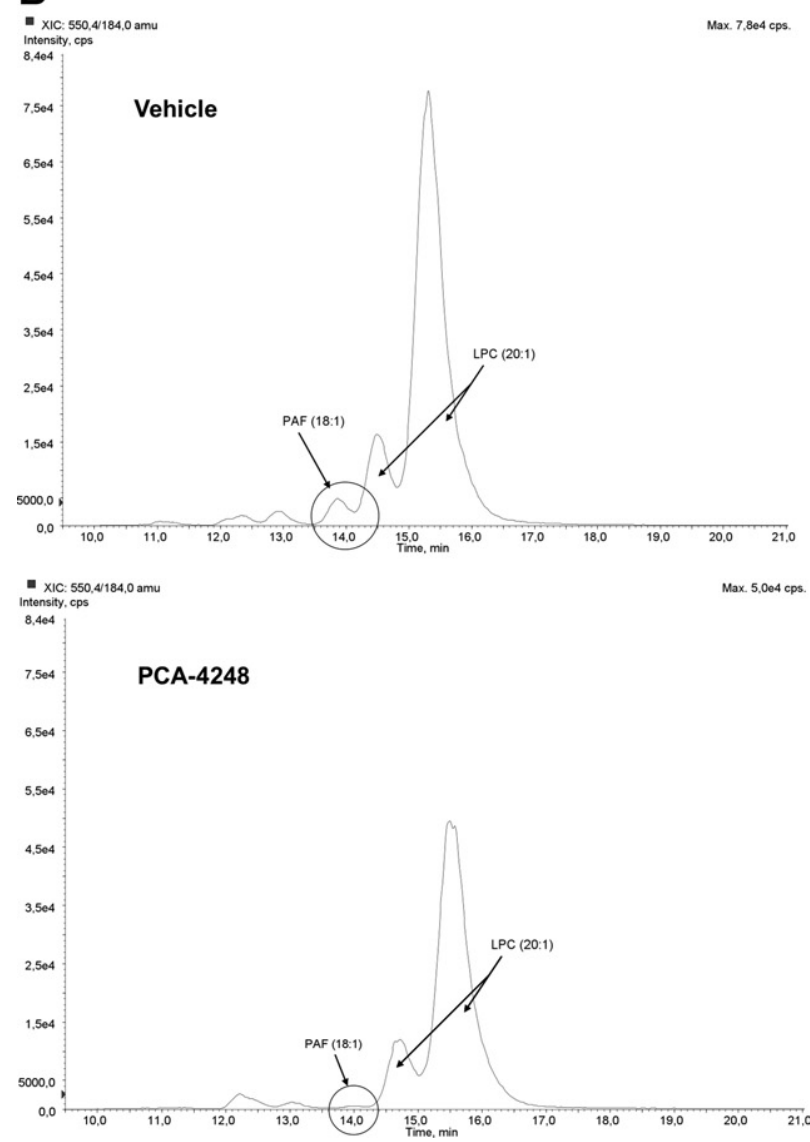

Figure 4. Both PCA-4248 and PUVA decrease the PAF level in the skin of K5.hTGF- $\beta 1$ transgenic mice. A: The PAF levels were analyzed in skin samples from WT or K5.hTGF- $\beta 1$ transgenic mice injected with either PCA- 4248 or its vehicle or transgenic mice treated with a subphototoxic $\left(0.25 \mathrm{~J} / \mathrm{cm}^{2}\right)$ or nearphototoxic $\left(0.50 \mathrm{~J} / \mathrm{cm}^{2}\right)$ dose of PUVA. Both PCA- 4248 and PUVA significantly decreased the level of PAF in dorsal skin of the transgenic mice, as detected by means of mass spectrometry. Data shown are pooled from two independent experiments, with $n=3$ to 7 per treatment group. ${ }^{*} P \leq 0.05$. ${ }^{* *} P \leq 0.01$. ${ }^{* * * *} P \leq$ 0.001 . B: Representative histogram of the results of mass spectrometric analysis of a sample from an individual K5.hTGF- $\beta 1$ transgenic mouse injected with either vehicle or PCA-4248. PAF (18:1), peak of PAF; LPC (20:1), peak of lysophosphatidylcholine. Error bars represent SEM.

psoriasis. ${ }^{23}$ The development and maintenance of psoriatic lesions have been linked to the secretion of cytokines and chemokines, including Th17-related cytokines, such as IL-17A, IL-17F, IL-23, IL-12, and IL-6. ${ }^{31}$ For instance, Teunissen et $\mathrm{al}^{32}$ showed detectable levels of $\mathrm{IL}-17$ mRNA in lesional psoriatic skin but not in nonlesional skin and that $\mathrm{CD}^{+}$and $\mathrm{CD}^{+}$clones derived from lesional psoriatic skin could produce IL-17 after stimulation with CD3/CD28 antibodies. The importance of the IL-17 pathway in K5.hTGF- $\beta 1$ mice is also supported by the observation that blocking by injection with anti-IL-17 monoclonal antibody also stops the progression of the psoriatic skin disease in the model. ${ }^{16}$ At first sight, this seems to contradict the study by Fitch et $\mathrm{al}^{33}$ suggesting that the inflammatory skin disease in their K5.hTGF- $\beta 1$ mice did not depend on the IL-23/Th17 pathway. However, the animals they used exhibited eosinophilic skin infiltration and highly elevated lesional IL-4 levels and high serum IgE levels, in contrast to the characteristics of the K5.hTGF- $\beta 1$ mice originally described by Li et al. ${ }^{14}$ The latter findings were confirmed in our study, in which the mice had normal expression of Th2 cytokines, including IL-4 (Figure 3A).

We also found that blockade of the PAF receptor with PCA-4248 significantly reduced neutrophil infiltration in the dermis of transgenic mice (Figure 2). This effect may have been mediated via negative regulation of leukotactic factors, such as the functional murine IL-8 homologues CXCL1/KC and CXCL2/MIP-2.5,34,35 This is of clinical relevance because the abundance of PAF, eg, induced by intradermal injection into human skin, induces local swelling, wheal and flare responses, intravascular congestion, and neutrophil accumulation with the development of a cellular infiltrate primarily composed of lymphocytes and histiocytes. ${ }^{17,36}$ This is in line with our finding that PAF injection into the skin accelerated the psoriatic phenotype of the transgenic mice (Table 1). It is also important to mention that there is evidence of cross talk between human neutrophils and Th17 cells by the way that IL-17A and IL-17F, two of several cytokines produced by Th17 cells, can indirectly induce the recruitment of neutrophils. ${ }^{37}$ Consequently, PCA-4248 treatment may also have diminished the accumulation of $\mathrm{CD} 8^{+}$cells and $\mathrm{CD}^{+}{ }^{+}$T cells in the dermis of transgenic mice (Figure 2).

In addition, we noted that blockade of the PAF receptor activated the transcription of COX-2 and the transcription and expression of $\mathrm{IL}-10$ in the skin (Figure 3, C and D) and its release in the serum (Figure $3 \mathrm{~A}$ ). The transcription of COX-2 after PAF receptor blockade may reflect the involvement of this enzyme in an antipsoriatic gene transcription process that includes $\mathrm{IL}-10$ establishment in K5.hTGF- $\beta 1$ transgenic mice. This finding is in line with reports by other researchers, ${ }^{38}$ who concluded that COX2-mediated prostaglandin $\mathrm{E}_{2}$ up-regulates IL-10, which down-regulates IL-12 production. ${ }^{39}$ At first glance, this contrasts with the results of previous studies, in which PAF was suggested to induce COX-2.,3,40 However, the differential outcome of COX-2 regulation by PAF may be explained by differences between the cytokine networks under pathologic conditions occurring in a disease model such as K5.hTGF- $\beta 1$ transgenic mice compared with physiologic conditions in normal cell culture ${ }^{5}$ or healthy mice.

The observation that IL-10 induced by PAF blockade may be responsible for inhibiting progression of the psoriatic phenotype in K5.hTGF- $\beta 1$ transgenic mice is intriguing because recombinant IL-10 has been shown to be clinically effective in the treatment of psoriasis in hu- 
mans $\mathrm{s}^{41,42}$ and is one of the main mediators of the effects of PUVA, ${ }^{27}$ another highly effective treatment modality of psoriasis. ${ }^{43}$ Importantly, the functional relevance and significance of PAF receptor blockade and the subsequent reduction of PAF in the K5.hTGF- $\beta 1$ transgenic mouse model are supported by findings from a previous study ${ }^{16}$ in which treatment during a 4-week period with the same doses of PUVA as used in this study led to improvement of the psoriatic phenotype of transgenic mice, accompanied by normalization of abnormally elevated cytokine levels in the skin and serum, including the Th1 and Th17 pathway and induction of IL-10. Similar to PUVA treatment of K.5hTGF- $\beta 1$ transgenic mice, we also observed on PCA4248 injection a decreased skin level of STAT3, a transcription factor that directly binds to the IL-17A and IL-17F promoters, ${ }^{44}$ analogous to other Th cell subsets, initiates Th17 commitment ${ }^{24,45}$ and links activated keratinocytes and immunocytes required for development of psoriasis in another transgenic mouse model. ${ }^{46}$ Furthermore, STAT3 has been shown to be an important regulator for other inflammatory cytokines, such as IL- $6^{47}$ and IL-12, ${ }^{48}$ both down-regulated by PAF blockade in this study (Figure 3 ). In this context, it has also been previously shown that STAT1 and STAT3 translocate to the nucleus after PAF stimulation, ${ }^{49}$ and there was attenuation of STAT3 phosphorylation by PAF receptor antagonists. ${ }^{50,51}$

Taken together, the results of this study demonstrate that binding of PAF to its receptor is essential for psoriatic disease progression in the K5.hTGF- $\beta 1$ transgenic mice and that PAF down-regulation and subsequent modulation of transcription factors such as STAT3 and downstream cytokine networks by a PAF receptor antagonist such as PCA-4248 or PUVA treatment has disease-suppressive activity. This implies that PAF blockade may be an option for the clinical development of antipsoriatic treatment. This particularly concerns less the chronic plaque type ${ }^{52}$ but more the inflammatory variants of the disease, such as localized pustular psoriasis (ie, palmoplantar psoriasis of Barber-Königsbeck or acrodermatitis continua of Hallopeau) $)^{53-55}$ and generalized pustular psoriasis (von Zumbusch type), ${ }^{56}$ which are characterized by massive neutrophilic accumulation with formation of microabscesses in the skin. The complications of the latter condition can be fatal, usually as a result of the protean manifestations of severe systemic disease, congestive heart failure, and intercurrent infections. There is an urgent need for new treatments for the latter conditions because antipsoriatic drugs, such as the biologicals (including anti-TNF- $\alpha$ and anti-IL-12/23 antibody), ${ }^{57}$ have been used only in single cases but have not yet been studied in controlled clinical trials and are not approved in these psoriasis variants. ${ }^{53-55}$ In addition, the blockade of PAF may be advantageous compared with other antipsoriatic strategies because it may confer additional anticarcinogenic efficacy, ${ }^{28}$ being of particular value for patients with psoriasis prone to skin cancer due to previous treatment. ${ }^{58}$ Moreover, interference with PAF and the downstream IL-17 pathway may also be attractive to prevent complications of comorbidities in psoriasis, especially metabolic syndrome and cardiovascular disease. ${ }^{59-61}$ Indeed, the IL-23/IL-17 axis is stimulated in obesity ${ }^{62}$ and can accelerate atherosclerosis. ${ }^{63}$ The blockade of PAF may not only offer the opportunity to down-regulate IL-17 and consequently diminish psoriatic skin manifestations, as shown herein, but may also prevent platelet aggregation ${ }^{64}$ and vasculopathy ${ }^{65}$ of psoriatic comorbidity.

\section{Acknowledgments}

We thank the staff of the Center for Medical Research (Medical University of Graz) for its continuous support, Ms. Ulrike Schmidbauer for providing expertise and support in performing immunohistochemical staining, and Dr. Xiao-Jing Wang (University of Colorado, Denver), for providing the original K5.hTGF- $\beta 1$ transgenic mouse strain.

\section{References}

1. Ishii S, Shimizu T: Platelet-activating factor (PAF) receptor and genetically engineered PAF receptor mutant mice. Prog Lipid Res 2000, 39:41-82

2. Mallet $A$, Cunningham $F$ : Structural identification of platelet activating factor in psoriatic scale. Biochem Biophys Res Commun 1985, 126 : 192

3. Walterscheid JP, Ullrich SE, Nghiem DX: Platelet-activating factor, a molecular sensor for cellular damage, activates systemic immune suppression. J Exp Med 2002, 195:171-179

4. Melnikova $V$, Bar-Eli M: Inflammation and melanoma growth and metastasis: the role of platelet-activating factor (PAF) and its receptor. Cancer Metastasis Rev 2007, 26:359-371

5. Pei Y, Barber LA, Murphy RC, Johnson CA, Kelley SW, Dy LC, Fertel $\mathrm{RH}$, Nguyen TM, Williams DA, Travers JB: Activation of the epidermal platelet-activating factor receptor results in cytokine and cyclooxygenase-2 biosynthesis. J Immunol 1998, 161:1954-1961

6. Maggi M, Bonaccorsi L, Finetti G, Carloni V, Muratori M, Laffi G, Forti G, Serio M, Baldi E: Platelet-activating factor mediates an autocrine proliferative loop in the endometrial adenocarcinoma cell line HEC1A. Cancer Res 1994, 54:4777-4784

7. Peri A, Bonaccorsi L, Cioppi F, Muratori M, Luconi M, Granchi S, Maggi M, Baldi E: The effects of an autocrine loop mediated by platelet-activating factor (PAF) in HEC-1A cells are reverted by uteroglobin. Hum Cell 2003, 16:95-99

8. Izaki S, Yamamoto T, Goto Y, Ishimaru S, Yudate F, Kitamura K Matsuzaki M: Platelet-activating factor and arachidonic acid metabolites in psoriatic inflammation. Br J Dermatol 1996, 134:1060-1064

9. Braverman IM, Sibley J: Role of the microcirculation in the treatment and pathogenesis of psoriasis. J Invest Dermatol 1982, 78:12-17

10. Andersen S, Sjursen W, Laegreid A, Volden G, Johansen B: Elevated expression of human nonpancreatic phospholipase $A 2$ in psoriatic tissue. Inflammation 1994, 18:1-12

11. Ramesha CS, Soter N, Pickett WC: Identification and quantitation of PAF from psoriatic scales. Agents Actions 1987, 21:382-383

12. Travers JB, Harrison KA, Johnson CA, Clay KL, Morelli JG: Plateletactivating factor biosynthesis induced by various stimuli in human HaCaT keratinocytes. J Invest Dermatol 1996, 107:88-94

13. Travers JB, Huff JC, Rola-Pleszczynski M, Gelfand EW, Morelli JG, Murphy RC: Identification of functional platelet-activating factor receptors on human keratinocytes. J Invest Dermatol 1995, 105:816-823

14. Li AG, Wang D, Feng XH, Wang XJ: Latent TGF $\beta 1$ overexpression in keratinocytes results in a severe psoriasis-like skin disorder. EMBO J 2004, 23:1770-1781

15. Han G, Williams CA, Salter K, Garl PJ, Li AG, Wang XJ: A role for TGF $\beta$ signaling in the pathogenesis of psoriasis. J Invest Dermatol 2010, 130:371-377

16. Singh TP, Schön MP, Wallbrecht K, Michaelis K, Rinner B, Mayer G, Schmidbauer U, Strohmaier H, Wang XJ, Wolf P: 8-Methoxypsoralen plus ultraviolet $A$ therapy acts via inhibition of the IL-23/Th17 axis and induction of Foxp3(+) regulatory T cells involving CTLA4 signaling in a psoriasis-like skin disorder. J Immunol 2010, 184:7257-7267 
17. Edwards LJ, Constantinescu CS: Platelet activating factor/platelet activating factor receptor pathway as a potential therapeutic target in autoimmune diseases. Inflamm Allergy Drug Targets 2009, 8:182-190

18. Bettelli $\mathrm{E}$, Oukka M, Kuchroo VK: T(H)-17 cells in the circle of immunity and autoimmunity. Nat Immunol 2007, 8:345-350

19. Brucklacher-Waldert V, Stuerner K, Kolster M, Wolthausen J, Tolosa E: Phenotypical and functional characterization of Thelper 17 cells in multiple sclerosis. Brain 2009, 132:3329-3341

20. Fletcher JM, Lonergan R, Costelloe L, Kinsella K, Moran B, O'Farrelly $\mathrm{C}$, Tubridy $\mathrm{N}$, Mills $\mathrm{KH}$ : $\mathrm{CD}{ }^{+}{ }^{+} \mathrm{Foxp}^{+}$regulatory $\mathrm{T}$ cells suppress pathogenic Th17 cells and are impaired in multiple sclerosis. J Immunol 2009, 183:7602-7610

21. Heo YJ, Joo YB, Oh HJ, Park MK, Heo YM, Cho ML, Kwok SK, Ju JH, Park KS, Cho SG, Park SH, Kim HY, Min JK: IL-10 suppresses Th17 cells and promotes regulatory $\mathrm{T}$ cells in the CD4(+) T cell population of rheumatoid arthritis patients. Immunol Lett 2010, 127:150-156

22. Pernis AB: Th17 cells in rheumatoid arthritis and systemic lupus erythematosus. J Intern Med 2009, 265:644-652

23. Di Cesare A, Di Meglio P, Nestle FO: The IL-23/Th17 axis in the immunopathogenesis of psoriasis. J Invest Dermatol 2009, 129: 1339-1350

24. Korn T, Oukka M, Kuchroo V, Bettelli E: Th17 cells: effector T cells with inflammatory properties. Semin Immunol 2007, 19:362-371

25. Bligh EG, Dyer WJ: A rapid method of total lipid extraction and purification. Can J Biochem Physiol 1959, 37:911-917

26. Matsumura Y, Byrne SN, Nghiem DX, Miyahara Y, Ullrich SE: A role for inflammatory mediators in the induction of immunoregulatory $B$ cells. J Immunol 2006, 177:4810-4817

27. Wolf $P$, Nghiem DX, Walterscheid JP, Byrne S, Matsumura Y, Bucana C, Ananthaswamy HN, Ullrich SE: Platelet-activating factor is crucial in psoralen and ultraviolet A-induced immune suppression, inflammation, and apoptosis. Am J Pathol 2006, 169:795-805

28. Sreevidya CS, Khaskhely NM, Fukunaga A, Khaskina P, Ullrich SE: Inhibition of photocarcinogenesis by platelet-activating factor or serotonin receptor antagonists. Cancer Res 2008, 68:3978-3984

29. Walterscheid JP, Nghiem DX, Kazimi N, Nutt LK, McConkey DJ, Norval M, Ullrich SE: Cis-urocanic acid, a sunlight-induced immunosuppressive factor, activates immune suppression via the 5-HT2A receptor. Proc Natl Acad Sci U S A 2006, 103:17420-17425

30. Martins MA, Lima MCR, Bozza PT, Neto HCCF, Silva PMR, Sunkel CE, Cordeiro RSB: Interference of the PAF receptor antagonist, PCA4248 , with the rat pleurisy evoked by inflammatory mediators or allergen. Eur J Pharmacol 1993, 237:17-22

31. Lowes MA, Bowcock AM, Krueger JG: Pathogenesis and therapy of psoriasis. Nature 2007, 445:866-873

32. Teunissen MB, Koomen CW, de Waal Malefyt R, Wierenga EA, Bos JD: Interleukin-17 and interferon- $\gamma$ synergize in the enhancement of proinflammatory cytokine production by human keratinocytes. J Invest Dermatol 1998, 111:645-649

33. Fitch EL, Rizzo HL, Kurtz SE, Wegmann KW, Gao W, Benson JM, Hinrichs DJ, Blauvelt A: Inflammatory skin disease in K5.hTGF- $\beta 1$ transgenic mice is not dependent on the IL-23/Th17 inflammatory pathway. J Invest Dermatol 2009, 129:2443-2450

34. Countryman NB, Pei Y, Yi Q, Spandau DF, Travers JB: Evidence for involvement of the epidermal platelet-activating factor receptor in ultraviolet-B-radiation-induced interleukin-8 production. J Invest Dermatol 2000, 115:267-272

35. Bussolino F, Arese M, Montrucchio G, Barra L, Primo L, Benelli R, Sanavio F, Aglietta M, Ghigo D, Rola-Pleszczynski MR: Platelet activating factor produced in vitro by Kaposi's sarcoma cells induces and sustains in vivo angiogenesis. J Clin Invest 1995, 96:940-952

36. Archer CB, Page CP, Morley J, MacDonald DM: Accumulation of inflammatory cells in response to intracutaneous platelet activating factor (PAF-acether) in man. Br J Dermatol 1985, 112:285-290

37. Pelletier M, Maggi L, Micheletti A, Lazzeri E, Tamassia N, Costantini C, Cosmi L, Lunardi C, Annunziato F, Romagnani S, Cassatella MA: Evidence for a cross-talk between human neutrophils and Th17 cells. Blood 2010, 115:335-343

38. Shreedhar V, Giese T, Sung VW, Ullrich SE: A cytokine cascade including prostaglandin E2, IL-4, and IL-10 is responsible for UVinduced systemic immune suppression, J Immunol 1998, 160:37833789

39. Harizi H, Juzan M, Pitard V, Moreau JF, Gualde N: Cyclooxygenase2-issued prostaglandin e(2) enhances the production of endogenous
IL-10, which down-regulates dendritic cell functions. J Immunol 2002, 168:2255-2263

40. Ramos G, Kazimi N, Nghiem DX, Walterscheid JP, Ullrich SE: Platelet activating factor receptor binding plays a critical role in jet fuelinduced immune suppression. Toxicol Appl Pharmacol 2004, 195 331-338

41. Reich K, Bruck M, Grafe A, Vente C, Neumann C, Garbe C: Treatment of psoriasis with interleukin-10. J Invest Dermatol 1998, 111:1235-1236

42. Reich K, Garbe C, Blaschke V, Maurer C, Middel P, Westphal G, Lippert $U$, Neumann C: Response of psoriasis to interleukin-10 is associated with suppression of cutaneous type 1 inflammation, downregulation of the epidermal interleukin-8/CXCR2 pathway and normalization of keratinocyte maturation. J Invest Dermatol 2001, 116:319-329

43. Legat FJ, Hofer A, Quehenberger F, Kahofer $P$, Kerl H, Wolf $P$ : Reduction of treatment frequency and UVA dose does not substantially compromise the antipsoriatic effect of oral psoralen-UVA. J Am Acad Dermatol 2004, 51:746-754

44. Chen Z, Laurence A, Kanno Y, Pacher-Zavisin M, Zhu BM, Tato C, Yoshimura A, Hennighausen L, O'Shea JJ: Selective regulatory function of Socs3 in the formation of $\mathrm{IL}-17$-secreting $\mathrm{T}$ cells. Proc Natl Acad Sci U S A 2006, 103:8137-8142

45. Mathur AN, Chang HC, Zisoulis DG, Stritesky GL, Yu Q, O'Malley JT, Kapur R, Levy DE, Kansas GS, Kaplan MH: Stat3 and Stat4 direct development of IL-17-secreting Th cells. J Immunol 2007. 178:4901-4907

46. Sano S, Chan KS, Carbajal S, Clifford J, Peavey M, Kiguchi K, Itami S, Nickoloff BJ, DiGiovanni J: Stat3 links activated keratinocytes and immunocytes required for development of psoriasis in a novel transgenic mouse model. Nat Med 2005, 11:43-49

47. Pflegerl P, Vesely $P$, Hantusch B, Schlederer M, Zenz R, Janig E, Steiner G, Meixner A, Petzelbauer P, Wolf P, Soleiman A, Egger G, Moriggl R, Kishimoto T, Wagner EF, Kenner L: Epidermal loss of JunB leads to a SLE phenotype due to hyper IL-6 signaling. Proc Natl Acad Sci U S A 2009, 106:20423-20428

48. de Paus RA, van de Wetering D, van Dissel JT, van de Vosse E: IL-23 and $\mathrm{IL}-12$ responses in activated human $\mathrm{T}$ cells retrovirally transduced with IL-23 receptor variants. Mol Immunol 2008, 45:3889-3895

49. Lukashova V, Asselin C, Krolewski JJ, Rola-Pleszczynski M, Stankova J: G-protein-independent activation of Tyk2 by the platelet-activating factor receptor. J Biol Chem 2001, 276:24113-24121

50. Deo DD, Axelrad TW, Robert EG, Marcheselli V, Bazan NG, Hunt JD: Phosphorylation of STAT-3 in response to basic fibroblast growth factor occurs through a mechanism involving platelet-activating factor, JAK-2, and Src in human umbilical vein endothelial cells: evidence for a dual kinase mechanism, J Biol Chem 2002, 277 : 21237-21245

51. Deo DD, Bazan NG, Hunt JD: Activation of platelet-activating factor receptor-coupled $\mathrm{G}$ alpha q leads to stimulation of $\mathrm{Src}$ and foca adhesion kinase via two separate pathways in human umbilical vein endothelial cells. J Biol Chem 2004, 279:3497-3508

52. Elbers ME, Gerritsen MJ, van de Kerkhof PC: The effect of topical application of the platelet-activating factor-antagonist, Ro 24-0238, in psoriasis vulgaris: a clinical and immunohistochemical study. Clin Exp Dermatol 1994, 19:453-457

53. Kasche A, Pfab F, Hein R, Athanasiadis GI, Ollert M, Ring J, EberleinKonig B: Severe psoriasis pustulosa palmaris et plantaris (BarberKonigsbeck) treated successfully with soluble tumour necrosis factor receptor fusion protein (etanercept). J Eur Acad Dermatol Venereol 2007, 21:255-257

54. Ahmad K, Rogers S: Two years of experience with etanercept in recalcitrant psoriasis. Br J Dermatol 2007, 156:1010-1014

55. Thielen AM, Barde C, Marazza G, Saurat JH: Long-term control with etanercept (Enbrel) of a severe acrodermatitis continua of Hallopeau refractory to infliximab (Remicade). Dermatology 2008 217:137-139

56. Trent JT, Kerdel FA: Successful treatment of Von Zumbusch pustular psoriasis with infliximab. J Cutan Med Surg 2004, 8:224-228

57. Nestle FO, Kaplan DH, Barker J: Psoriasis. N Engl J Med 2009, 361:496-509

58. Kreimer-Erlacher H, Seidl H, Back B, Cerroni L, Kerl H, Wolf P: High frequency of ultraviolet mutations at the INK4a-ARF locus in 
squamous cell carcinomas from psoralen-plus-ultraviolet-A-treated psoriasis patients. J Invest Dermatol 2003, 120:676-682

59. Boehncke S, Thaci D, Beschmann H, Ludwig RJ, Ackermann H, Badenhoop K, Boehncke WH: Psoriasis patients show signs of insulin resistance. Br J Dermatol 2007, 157:1249-1251

60. Gottlieb AB, Dann F: Comorbidities in patients with psoriasis. Am J Med 2009, 122:1150.e1-9

61. Nijsten T, Wakkee M: Complexity of the association between psoriasis and comorbidities. J Invest Dermatol 2009, 129:1601-1603

62. Sumarac-Dumanovic M, Stevanovic D, Ljubic A, Jorga J, Simic M, Stamenkovic-Pejkovic D, Starcevic V, Trajkovic V, Micic D: Increased activity of interleukin-23/interleukin-17 proinflammatory axis in obese women. Int J Obes (Lond) 2009, 33:151-156
63. Pejnovic N, Vratimos A, Lee SH, Popadic D, Takeda K, Akira S, Chan WL: Increased atherosclerotic lesions and Th17 in interleukin-18 deficient apolipoprotein E-knockout mice fed high-fat diet. Mol Immunol 2009, 47:37-45

64. Rasheed H, Saeed SA: Involvement of thromboxane A2 and tyrosine kinase in the synergistic interaction of platelet activating factor and calcium ionophore A23187 in human platelet aggregation. Exp Mol Med 2004, 36:220-225

65. Crawford SE, Huang L, Hsueh W, Takami H, Gonzalez-Crussi F, Backer CL, Mu Y, Liu H, Mavroudis C: Captopril and platelet-activating factor (PAF) antagonist prevent cardiac allograft vasculopathy in rats: role of endogenous PAF and PAF-like compounds. J Heart Lung Transplant 1999, 18:470-477 